\title{
Modulatory Effects of Galanin in the Lateral Bed Nucleus of the Stria Terminalis on Behavioral and Neuroendocrine Responses to Acute Stress
}

\author{
Habibeh Khoshbouei, Ph.D., Marco Cecchi, Ph.D., and David A. Morilak, Ph.D.
}

The neuropeptide galanin has been identified as a possible neurotransmitter/neuromodulator within the central nervous system. In the present study, a potential role for galanin in the lateral bed nucleus of the stria terminalis (BSTL) in modulating behavioral and neuroendocrine responses to an acute stress was investigated. In the first experiment, acute immobilization stress induced anxietylike behavioral responses in rats, measured on the social interaction and elevated plus-maze tests. Immobilization stress decreased both social interaction time and open arm exploratory behavior on the elevated plus-maze. Bilateral administration of the galanin antagonist M40 (1.0 nmole) $0.2 \mu l$ ) into BSTL immediately prior to stress exposure attenuated the anxiogenic-like effects of immobilization stress, restoring both social interaction time and exploration of open arms to control levels. Administration of the antagonist alone had no effect on baseline behavior of unstressed control rats in either test, suggesting that the modulatory effect of galanin elicited during stress is not exerted tonically in unstressed animals. In the second experiment, immobilization stress produced an increase in plasma adrenocorticotropic hormone (ACTH) that was also attenuated by bilateral administration of M40 into BSTL prior to stress. These results suggest that during stress, the neuropeptide galanin exerts a modulatory effect in the $B S T L$, facilitating behavioral and neuroendocrine components of the acute stress response.

[Neuropsychopharmacology 27:25-34, 2002]

(C) 2002 American College of Neuropsychopharmacology.

Published by Elsevier Science Inc.
Since its discovery (Tatemoto et al. 1983), the peptide neurotransmitter galanin has been implicated in numerous autonomic and physiologic regulatory processes, including feeding (Crawley 1999), cardiovascular control (Shih et al. 1996), learning and memory (McDonald

From the Department of Pharmacology, University of Texas Health Science Center at San Antonio, 7703 Floyd Curl Drive, San Antonio, TX 78229-3900.

Address correspondence to: David Morilak, Ph.D., Department of Pharmacology, University of Texas Health Science Center, 7703 Floyd Curl Drive, San Antonio, TX 78229-3900, Tel.: (210) 567-4174, Fax: (210) 567-4303, E-mail: morilak@uthscsa.edu

Received August 6, 2001; revised November 26, 2001; accepted December 4, 2001.

Online publication: $12 / 20 / 01$ at www.acnp.org/citations/ Npp122001218. et al. 1998), and the response to stress (Holmes et al. 1995; Khoshbouei et al. 2000; Sweerts et al. 1999, 2000). Furthermore, it has been hypothesized that galanin may also be involved in disease states such as depression (Seutin et al. 1989), feeding disorders (Crawley et al. 1990, 1993), and Alzheimer's disease (Bartfai et al. 1992; Mufson et al. 1993, 1998, 2000).

Limbic forebrain structures important for the expression of fear and anxiety, such as the central nucleus of the amygdala and the bed nucleus of the stria terminalis (BST), show a rich expression of galanin and galanin receptors (Bartfai et al. 1992; Gustafson et al. 1996; Melander et al. 1986a,b). Within the BST, there is extensive overlap between galanin-immunoreactive terminals and galanin receptors (Gray and Magnuson 1987b; Miller et 
al. 1993b, 1997). The BST is a component of the "extended amygdala", which plays a critical role in the integration of autonomic and behavioral responses to stress (Davis and Shi 1999; Davis et al. 1997a; Herman and Cullinan 1997). The lateral BST (BSTL) in particular has been implicated in modulation of behavioral-affective responses (Cecchi et al. 2001; Davis and Shi 1999). Lesions of the BST blocked the enhancement of acoustic startle induced by i.c.v. infusion of CRH (Davis et al. 1997b). Similarly, blockade of glutamate receptors in BSTL antagonized the unconditioned potentiation of startle induced by exposure to bright light (reviewed by (Davis and Shi 1999)).

In addition to playing a potential role in modulating the behavioral response to stress, the BSTL also exerts an extrahypothalamic modulatory influence on stressinduced hypothalamic-pituitary-adrenal (HPA) activation (Cecchi et al. 2001; Herman and Cullinan 1997; Herman et al. 1996). While some investigators have suggested that the BST has an inhibitory influence on HPA activation (Herman and Cullinan 1997), others have suggested a facilitatory role. A small cluster of CRF-immunoreactive neurons in ventrolateral BST project to mid-parvocellular PVN (Moga and Saper 1994). Lesions of BST attenuated the increase in plasma ACTH and corticosterone induced by reintroduction of rats into a context in which they had previously been exposed to foot shock (Gray et al. 1993), and specific lesioning of anterolateral BST cause a decrease in CRF mRNA in the PVN (Herman et al. 1994).

Administration of galanin directly into the hypothalamic paraventricular nucleus has been shown to reduce activation of the HPA axis induced by acute ether-stress (Hooi et al. 1990), but what effects galanin may exert specifically in the BSTL in modulating stress-induced neuroendocrine responses are currently unknown. Galanin innervation of BSTL may originate in part from ascending brainstem noradrenergic afferents. Galanin is extensively co-localized with norepinephrine in ascending afferents from the locus coeruleus to the limbic forebrain (Holets et al. 1988; Melander et al. 1986c,d; Sawchenko and Pfeiffer 1988; Xu et al. 1998). However, the primary noradrenergic innervation of BST arises from the medullary A1 and A2 cell groups (Delfs et al. 2000). Thus, another source of galanin in the BSTL may arise from local galanin-synthesizing neurons found in the BST itself. Within the BST, there are at least two distinct subpopulations of galaninergic neurons. One group co-expresses vasopressin, and projects to the lateral septum and midbrain central gray (Gray and Magnuson 1987a,b; Miller et al. 1993a, 1997). A second group does not express vasopressin, and their projection targets outside the BST are unknown (Gray and Magnuson 1987a). The stress-reactivity of the galanin neurons in BSTL is unknown. However, galanin neurons in the central nucleus of the amygdala, another component of the extended amygdala that is closely related to the BST, have been shown to be stress responsive, as prepro-galanin mRNA expression is increased following restraint stress (Sweerts et al. 1999).

Noradrenergic afferent terminals have been shown to contact galanin-positive targets in the bed nucleus of stria terminalis (Kozicz 1999). The ascending noradrenergic system is activated by stress (Abercrombie and Jacobs 1987; Morilak et al. 1987; Pacak et al. 1993), and it has been demonstrated that stress-induced activation of the noradrenergic input to BSTL can facilitate both behavioral reactivity and activation of the HPA axis in response to stress (Cecchi et al. 2001; Delfs et al. 2000; Shaham et al. 2000). Recent studies have suggested a mutually antagonistic interaction between galanin and norepinephrine acting at $\alpha_{2}$ adrenergic receptors (DiazCabiale et al. 2000a,b). Thus, whether galanin release from local neurons is affected by noradrenergic afferent activity, or is co-released directly from a subset of noradrenergic terminals innervating BST, both possibilities suggest that galanin might play a role in modulating stress-induced behavioral reactivity and stress-induced HPA activation in the BSTL.

The galanin antagonist M40 (Bartfai et al. 1993) has been shown in vivo to block the effects of exogenous galanin administration on memory tasks (McDonald and Crawley 1996) and food intake (reviewed in Crawley 1999). Thus, in this experiment, we administered M40 directly into BSTL to address the potential role of endogenous galanin in modulating behavioral and neuroendocrine responses to acute stress. This approach has been used previously in our laboratory to demonstrate modulatory effects of galanin in the central nucleus of the amygdala (Khoshbouei et al. 2001). Portions of this work have been presented in abstract form (Khoshbouei et al. 2000).

\section{MATERIALS AND METHODS}

\section{Animals}

Fifty-three adult male Sprague Dawley rats (Harlan, Indianapolis), weighing approximately 225-250 g upon arrival, were housed in groups of three in a room adjacent to the testing rooms. They were maintained on $12 / 12 \mathrm{~h}$ light/dark cycle (lights on at 7 A.M.). The animals were acclimated to the housing facility for one week prior to any experimental procedure. Experiments were conducted between 9 A.M. and 2 P.M., during the light portion of the cycle. Food and water were available ad libitum. All procedures were reviewed and approved by the Institutional Animal Care and Use Committee of the University of Texas Health Science Center at San Antonio.

\section{Experiment 1: Modulation of Behavioral Reactivity to Acute Stress by Galanin in the BSTL}

To assess the behavioral effects of galanin in BSTL during the response to acute stress, 34 rats were randomly 
assigned to groups defined by the drug administered into BSTL (vehicle or the galanin antagonist M40 [0.2 or $1.0 \mathrm{nmol}]$ ) and the stress condition (5 min immobilization stress or unstressed). Only the highest dose of M40 was given to unstressed rats, resulting in five groups total. M40 (American Peptide) was dissolved in filtered distilled water at concentrations of 1.98 or $9.91 \mathrm{mg} / \mathrm{ml}$. Aliquots were stored at $-80^{\circ} \mathrm{C}$ until use. Each aliquot was thawed and used only once.

Rats weighing 275-300 g at the time of surgery were anethetized and placed in a stereotaxic apparatus. Guide cannulae, consisting of two lengths of 22 gauge stainless steel tubing (Small Parts), were implanted bilaterally, so as to position the tips $1.0 \mathrm{~mm}$ above the BSTL (coordinates from bregma: AP $-0.4 \mathrm{~mm}$, ML $\pm 3.5 \mathrm{~mm}$, DV $-7.0 \mathrm{~mm}$, incisor set at $-3.3 \mathrm{~mm}$, approached at a $15^{\circ}$ lateral angle). The guide cannulae were fitted with 30 gauge obdurators, and anchored to the skull with four jewelers' screws and acrylic dental cement. Following all surgical preparations, animals were housed individually for seven days prior to testing. The rats were handled for 5 min during each of the five days prior to testing. On each of the three days before testing, each rat was familiarized with the social interaction arena by placing it in the apparatus individually for $5 \mathrm{~min}$.

On the day of the experiment, the obdurators were removed from the guide cannulae and replaced with 30 gauge stainless steel microinjectors (Small Parts) extending $1.0 \mathrm{~mm}$ beyond the tip of the cannulae, placing them in the BSTL. The microinjection cannulae were connected by PE-10 polyethylene tubing to a Hamilton syringe mounted on a syringe pump. Bilateral microinjections of vehicle, or the galanin antagonist M40 ( 0.2 or 1.0 nmole per side) were made into the BSTL. These doses of M40 were shown to be effective in previous studies by us (Khoshbouei et al. 2001) and by others (Crawley et al. 1993; McDonald and Crawley 1996). All drugs were injected in a volume of $0.2 \mu \mathrm{l}$ at a rate of $0.2 \mu \mathrm{l} / \mathrm{min}$. It was determined in a series of pilot studies that similar injections of dye were restricted to BSTL. After completing the microinjections, cannulae were left in place for $3 \mathrm{~min}$ before withdrawing.

Following microinjections, unstressed animals were returned immediately to their holding cages lined with home bedding, and stressed rats were subjected to 5-min immobilization stress as described previously (Khoshbouei et al. 2001). Briefly, animals were placed supine on top of a flat, plastic rack large enough to securely support the entire body $(26 \mathrm{~cm} \times 13 \mathrm{~cm})$. The limbs were taped gently but securely to the rack with medical adhesive tape, and strips of tape were placed across the animal's neck and back of the head to prevent excessive head movements. Care was taken to avoid applying undue pressure on the limbs with the tape, and the animals were monitored constantly throughout the procedure. After $5 \mathrm{~min}$ of immobiliza- tion, the animals were removed and returned to their holding cages lined with home bedding for $15 \mathrm{~min}$. Unstressed animals were left undisturbed in their cages for an equivalent amount of time. Immediately following the 15-min post-stress recovery period, rats were tested first on the social interaction test, followed immediately by the elevated plus maze (Fernandes et al. 1997; File et al. 1999).

The social interaction test arena consisted of a white wooden box, $60 \times 60 \mathrm{~cm}$, with $40 \mathrm{~cm}$ high walls. Testing took place under normal ambient overhead laboratory lighting conditions (light intensity 360 lux, measured in the center of the SI arena). The experimental rats were placed in the arena along with a second weightmatched stimulus rat (within $10 \mathrm{~g}$ total body weight), which had been previously familiarized with the arena and the test procedure. The two rats were placed in opposite corners of the arena, facing away from each other. Behavior during the 5-min test was recorded by a video camera for subsequent analysis by an experimenter who was blind to both the drug and stress treatment conditions of the test animal. The dependent measure in this test was the time spent engaged in active social interaction initiated by the test animal. Such behaviors included sniffing, climbing on, crawling under, following, grooming, or wrestling (File 1980; File and Hyde 1978, 1979).

Immediately after the end of the social interaction test, the rats were tested for $5 \mathrm{~min}$ in the elevated plusmaze. The elevated plus-maze (AccuScan Instruments, Inc.) consisted of four white plastic arms, $10 \times 50 \mathrm{~cm}$, oriented in the shape of a cross, intersecting at a $10 \times 10$ $\mathrm{cm}$ central platform. Two arms situated opposite each other were enclosed by walls $48 \mathrm{~cm}$ high ("closed arms"). The remaining two "open arms" had no walls, but were fitted with a $0.5 \mathrm{~cm}$ clear plastic rim around the edge to prevent animals falling off (Fernandes and File 1996). The elevation of the plus-maze was $100 \mathrm{~cm}$ above the floor. Testing took place under normal ambient overhead lighting conditions (light intensity 200 lux measured in the open arms). Dual infrared sensor beams were positioned at the entry of each arm; the sensors provided automated measures of the number of entries and the amount of time spent in the central platform, and in each of the closed arms and open arms (for details, see Khoshbouei et al. 2001). Open-to-Total Ratios (OTR) were calculated for Entries and for Time. The OTR, defined as the proportion of entries or time spent in the open arms relative to the total number of entries or total time spent in all arms (open/open + closed) were analyzed as indices of open-arm exploration that are independent of differences in overall locomotor activity. Conversely, the number of entries made into the closed arms was taken as an indicator of general locomotor activity independent of OTR (File 1984, 1995; File and Fluck 1994). After testing, rats were sacrificed, and 
anatomical localization of the injection sites in sections through the BSTL were determined histologically after counterstaining with cresyl violet. Cases in which one or both injection sites were located outside the BSTL were excluded from analyses a priori.

\section{Experiment 2: Modulation of Stress-induced ACTH Secretion by Galanin in the BSTL}

To assess the effects of galanin in BSTL on acute stressinduced ACTH secretion, 19 rats were randomly assigned to two groups, defined by the drug administered into BSTL (vehicle or M40). Rats weighing 275-300 g at the time of the surgery were anesthetized as above. An indwelling silastic catheter was implanted into the jugular vein, exteriorized at the back of the neck, and loaded with heparinized saline $(1000 \mathrm{U} / \mathrm{ml})$ to maintain patency. The rats were then placed in a stereotaxic apparatus and implanted bilaterally with guide cannulae aimed at the BSTL, also as above. Following recovery from surgery, animals were housed individually for seven days prior to testing.

On the day of the experiment, microinjection cannulae were placed in the BSTL as above. The intravenous catheter was connected to a 1-ml syringe, and a baseline blood sample $(0.2 \mathrm{ml})$ was withdrawn for determination of plasma ACTH levels. Preliminary experiments showed that microinjections of neither vehicle nor M40 into BSTL had any effect on basal ACTH levels (data not shown). Thus, only one baseline measure was taken immediately prior to drug microinjections. Immediately after withdrawal of the baseline blood sample, bilateral microinjections were made into the BSTL of vehicle or the galanin antagonist M40 (1 nmole). All injections were made in a volume of $0.2 \mu \mathrm{l}$ at a rate of $0.2 \mu \mathrm{l} / \mathrm{min}$. Following completion of the microinjections, cannulae were left in place for $3 \mathrm{~min}$ before withdrawing.

Immediately after the microinjections, rats were subjected to 30-min immobilization stress as described above. Blood samples were obtained at $5 \mathrm{~min}$ and 30 min during immobilization. After 30 min stress, the animals were returned to their home cage, and two additional blood samples were obtained at $15 \mathrm{~min}$ and 30 min after the end of the stress. After each blood sample, the withdrawn volume was immediately replaced by infusing an equivalent volume $(0.2 \mathrm{ml})$ of sterile saline.

Blood samples were collected into microfuge tubes containing $2 \mu \mathrm{l}$ of $0.5 \mathrm{M}$ EDTA. The samples were separated by centrifugation ( $3000 \mathrm{rpm}$ for $12 \mathrm{~min}$ at $4^{\circ} \mathrm{C}$ ), and plasma was removed, frozen and stored at $-80^{\circ} \mathrm{C}$ until assay. Plasma ACTH levels were determined by a commercially available radioimmunoassay (Nichols Institute). The detection limit of the assay was $15 \mathrm{pg} / \mathrm{ml}$. Intra- and inter-assay coefficients of variation were $9 \%$ and $11 \%$, respectively.
Following all experiments, placement of the injection cannulae in BSTL were verified histologically as above. Cases in which one or both injection sites were located outside the BSTL were eliminated from analyses a priori.

\section{Data Analyses}

For all experiments, data were analyzed by ANOVA, with repeated measures where appropriate. Significance was determined at $p<.05$. Where ANOVA indicated significant main effects or interactions, post-hoc comparisons were made using the Fisher's PLSD test.

\section{RESULTS}

\section{Experiment 1: Modulation of Stress-induced Anxiety by Galanin Antagonist in the BSTL}

Social Interaction Test. In the analysis of the effects of M40 on the stress-induced behavioral response in the social interaction test, ANOVA indicated a significant main treatment effect $\left(\mathrm{F}_{4,29}=4.985, p<.01\right)$. Subsequent post hoc analyses showed that immobilization stress induced a significant decrease in social interaction time in vehicle-injected animals, indicative of an anxiety-like behavioral response to stress (Figure 1). Bilateral injection of M40 alone (1.0 $\mathrm{nmol})$ into BSTL, in the absence of stress, had no effect on baseline behavior in the SI test. By contrast, bilateral administration of the galanin antagonist into the BSTL of stressed rats significantly attenuated the stress-induced reduction in social behavior at the highest dose, restoring social interaction time to a level that was no different from unstressed vehicle-injected control rats (Figure 1).

Elevated plus-maze. With M40 administration into the BSTL prior to immobilization stress, ANOVA revealed a significant main treatment effect on OTR for both Time $\left(\mathrm{F}_{4,29}=10.624, p<.0001\right)$ and Entries $\left(\mathrm{F}_{4,29}=2.663\right.$ $p<.05)$. Subsequent post hoc analyses showed that immobilization stress induced an anxiogenic-like behavioral response, i.e., a decrease in open-arm exploration, indicated by a significant reduction in OTR compared with the unstressed control group (Figure 2). As seen in the SI test, M40 administration alone in the BSTL of unstressed rats had no effect on baseline OTR in the elevated plus maze compared with vehicle-injected controls. However, the highest dose of M40 (1 nmole), microinjected into BSTL prior to stress, blocked the anxiogenic-like effects of immobilization stress and reversed the stressinduced reductions in OTR (Figure 2). A similar pattern of response was observed when OTR for either Time or Entries were analyzed. Neither Stress nor M40 had any effects on general Locomotor Activity, measured by number of closed-arm entries $\left(\mathrm{F}_{4,29}=0.309\right.$, n.s., data not shown). 


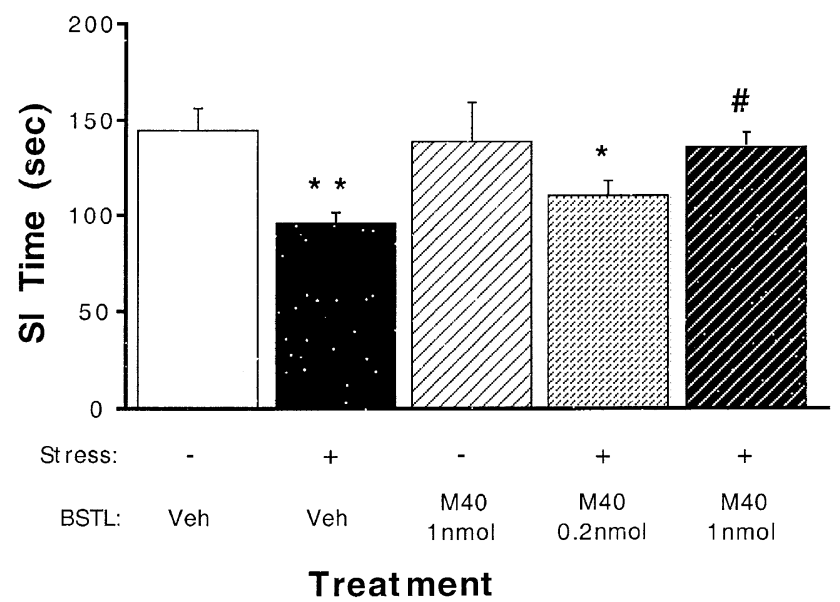

Figure 1. Galanin antagonist M40 in the BSTL attenuated stress-induced behavioral reactivity in the SI test. Bilateral administration of the galanin antagonist M40 (0.2-1.0 nmole) into BSTL attenuated the anxiety-like reduction in social interaction time induced by acute immobilization stress. In the absence of stress, M40 had no effect. Values represent the mean \pm S.E.M. $(\mathrm{n}=5-9) .{ }^{*} p<.05$ compared with unstressed vehicle controls; ${ }^{* *} p<.01$ compared with unstressed vehicle controls; ${ }^{\#} p<.05$ compared with the vehicle-treated stress group.

\section{Experiment 2: Modulation of Stress-induced ACTH Secretion by Galanin Antagonist in the BSTL}

When the effects of M40 administration into BSTL on stress-induced ACTH secretion were analyzed, ANOVA with repeated measures revealed significant main effects of Time $\left(\mathrm{F}_{4,68}=37.312, p<.01\right)$, Drug $\left(\mathrm{F}_{1,17}=7.1222, p<\right.$ $.01)$, and a significant Time $X$ Drug interaction $\left(\mathrm{F}_{4,68}=\right.$ $2.44, p<.05)$. Subsequent post hoc analyses indicated that microinjection of the galanin antagonist into BSTL significantly attenuated the increase in plasma ACTH measured after 30 min stress (Figure 3).

\section{Histological Localization}

Out of 59 rats total used for microinjections, six subjects were eliminated because one or both injection sites were determined to be outside of the BSTL, resulting in a total of 53 rats in which the microinjections were localized bilaterally to the BSTL (Figure 4). In those cases in which M40 microinjections were made outside the BSTL, there were no observable effects on either behavioral responses to stress or stress-induced ACTH secretion, as compared with vehicle injections made within the BSTL, suggesting that the effects of M40 were specific to BSTL.

\section{DISCUSSION}

In this study, we investigated a possible role for galanin in the BSTL in modulating neuroendocrine and behav-
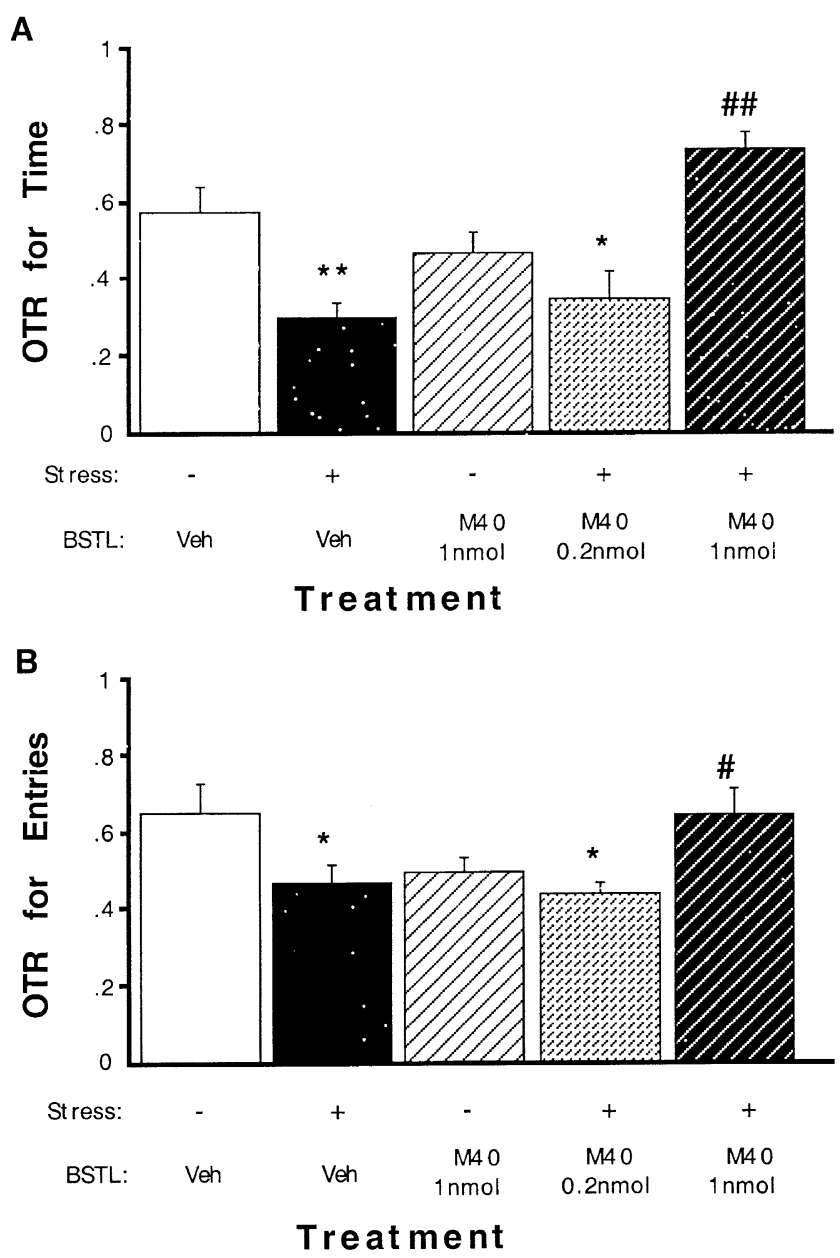

Figure 2. Galanin antagonist M40 in the BSTL attenuated stress-induced behavioral reactivity measured on the elevated plus-maze. Bilateral administration of M40 (0.2-1.0 nmole) into BSTL attenuated the anxiety-like reduction in open arm exploration on the elevated plus-maze induced by acute immobilization stress. In the absence of stress, M40 had no effect. A: Exploratory behavior on the open arms measured as OTR for Time. B: Exploratory behavior in the open arms measured as OTR for Entries. Values represent the mean \pm S.E.M. ( $\mathrm{n}=5-9) .{ }^{*} p<.05$ compared with the unstressed control group; ${ }^{* *} p<.01$ compared with the unstressed control group; ${ }^{\#} p<.05$ compared with the vehicle-treated stress group; \#\# $p<.001$ compared with the vehicle-treated stress group.

ioral-affective components of the acute stress response. In the first experiment, we examined the effect of the galanin antagonist M40 administered into the BSTL on behavioral reactivity to stress as measured by changes in social behavior and open-arm exploration on the social interaction test and elevated plus maze, respectively. In this experiment, M40 attenuated the reduction in both social behavior and exploratory behavior induced by acute immobilization stress, suggesting that endogenous galanin released in the BSTL facilitated acute behavioral reactivity to stress. In the second experiment, 


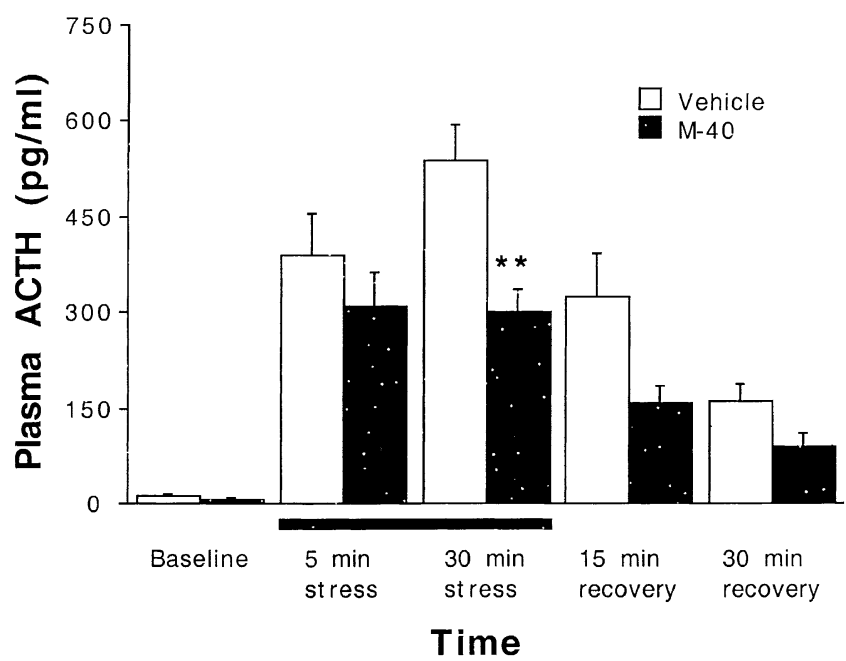

Figure 3. Galanin antagonist M40 in the BSTL attenuated stress-induced ACTH secretion. Bilateral administration of M40 (1.0 nmole) into BSTL attenuated the increase in plasma ACTH level induced by acute immobilization stress (Bar). All time points during and after stress were significantly elevated in both groups relative to their respective baselines. Values represent the mean \pm S.E.M. $(\mathrm{n}=8-11) .{ }^{* *} p<.01$ compared with the vehicle-treated control group.

we examined the effect of the galanin antagonist administered into the BSTL on a stress-induced neuroendocrine response, the activation of the HPA axis, indicated by secretion of ACTH into the peripheral circulation. We demonstrated that bilateral administration of M40 into the BSTL prior to stress attenuated activation of the HPA axis by about $40 \%$. These observations together suggest that stress-induced release of galanin in the BSTL facilitated both behavioral reactivity and HPA activation in response to acute stress.
Under unstressed baseline conditions, administration of the galanin antagonist into BSTL had no effect on either of the behavioral measures, suggesting that in the absence of an activating stimulus, such as an acute stressor, galanin exerts little or no tonic modulatory effect in the BSTL on these behaviors. This observation is consistent with the demonstration that the release of galanin, like that of other neuropeptides, seems to require that a relatively high level of electrical activity be induced in the presynaptic terminal (Consolo et al. 1994).

The bed nucleus of the stria terminalis is a limbic forebrain structure that has been implicated in modulation of both behavioral and neuroendocrine responses to stress (Cecchi et al. 2001; Delfs et al. 2000; Shaham et al. 2000; Herman and Cullinan 1997). In behavioral studies, microinjection of corticotropin-releasing hormone (CRH) directly into BSTL enhanced the startle response, and lesions centered on the BSTL blocked the potentiation of startle induced by i.c.v. infusion of CRH (Lee and Davis 1997). Inhibition of BST prevented the reduction in social interaction induced by peripheral lactate infusion in rats made sensitive to lactate by chronic inhibition of GABA synthesis in the dorsomedial hypothalamus (Shekhar and Keim 2000). The BST was shown to be activated during acute morphine withdrawal, and $\beta$-adrenergic receptor blockade attenuated both the activation of BST and the behavioral expression of opiate withdrawal (Aston-Jones et al. 1999). We have demonstrated recently that blockade of $\alpha_{1}$ or $\beta$-adrenergic receptors in BSTL attenuated stressinduced behavioral reactivity on the elevated plusmaze, (Cecchi et al. 2001). In the same study, we also provided evidence that the BSTL plays a role in stressinduced activation of the HPA axis, as we showed that blockade of $\alpha_{1}$ adrenergic receptors, but not $\beta$-recep-

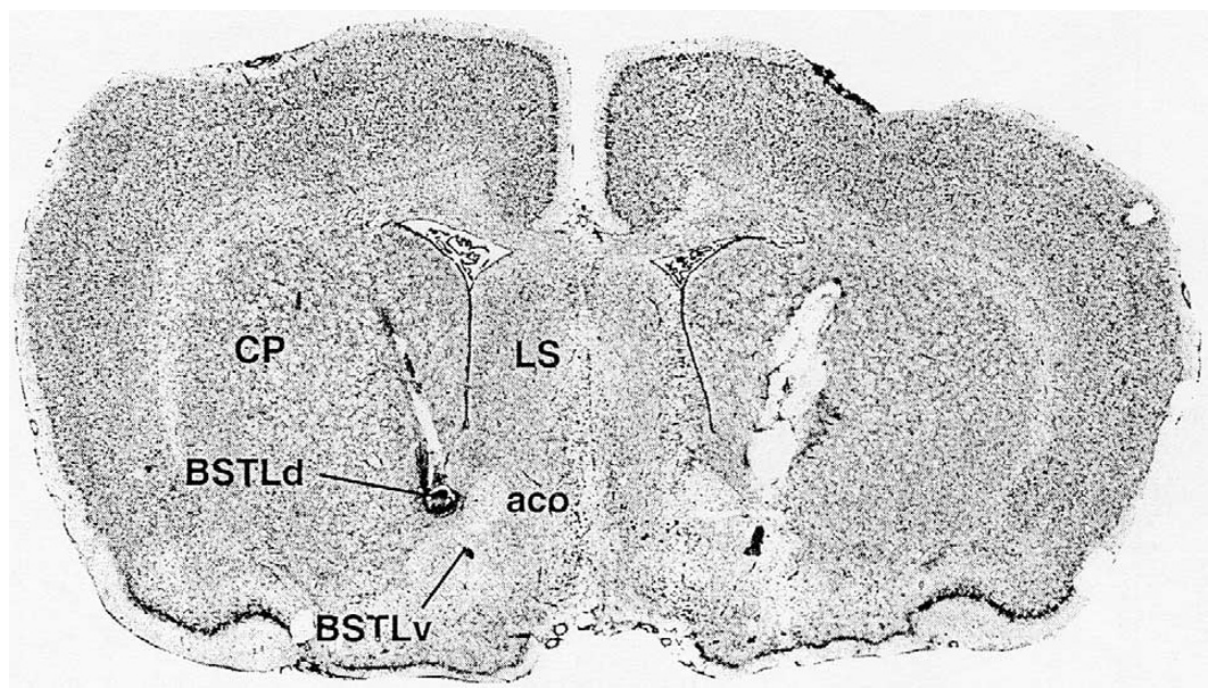

Figure 4. Histological localization of microinjection sites to BSTL. In this representative example of a Cresyl-stained section cut through the forebrain, the tips of the microinjection cannulae tracks are shown to be located bilaterally in the ventral BSTL (BSTLv), after passing through the dorsal BSTL (BSTLd). LS, lateral septum; CP, caudate-putamen; aco, anterior commissure. 
tors, attenuated stress-induced ACTH secretion (Cecchi et al. 2001). Further, lesions specifically of anterolateral BST decreased expression of CRH mRNA in the PVN (Herman et al. 1994), and reduced corticosterone secretion induced by conditioned stress (Gray et al. 1993). A possible substrate for the facilitatory influence of BSTL on the HPA axis was suggested by anatomical studies showing that a cluster of CRH neurons in the BSTL project directly to the PVN (Moga and Saper 1994). Thus, a body of evidence suggests that activation of the BST, and perhaps specifically the BSTL, facilitates both behavioral and neuroendocrine reactivity to acute stress.

However, there is also evidence for a possible inhibitory function of the BSTL. It has been proposed that the BST and related regions of the pre-optic area inhibit HPA activation via inhibitory GABAergic projections to the PVN (Herman and Cullinan 1997). A more complex organization was suggested in a study conducted in anesthetized rats, in which electrical stimulation of the medial BST increased, whereas lateral BST decreased basal corticosterone secretion (Dunn 1987). It has been reported that norepinephrine suppresses electrical activity in the BST (Sawada and Yamamoto 1981), and inhibits glutamate release in BST (Forray et al. 1999), suggesting that NE exerts an inhibitory tone over information flow mediated in the BST by glutamate. This could imply that the results described above after adrenergic antagonist administration into BST could represent a disinhibitory rather than an excitatory effect, which would consequently imply that the functional output of the BST may itself be inhibitory on behavioral and neuroendocrine reactivity. Such an interpretation would make the results of the present study consistent with the predominantly inhibitory cellular effects that have been observed for galanin.

Galanin administration onto LC neurons in vitro consistently causes a slowly developing inhibition of spontaneous activity accompanied by hyperpolarization and a decrease in membrane resistance (Pieribone et al. 1998, 1995). Many of these inhibitory effects are mediated by the GAL-R1 receptor subtype, which couples to Gi/o type G-proteins, reducing cAMP formation, closing voltage-sensitive calcium channels, and opening ATP-sensitive potassium channels (Branchek et al. 2000; Waters and Krause 2000). Galanin has been shown to inhibit forskolin-stimulated adenylate cyclase activity in hippocampus and cortex (Waters and Krause 2000; Xu et al. 1999), and to inhibit the stimulation of cAMP induced by norepinephrine in rat cerebral cortex (Branchek et al. 1998, 2000). Thus, in the present experiment, it is possible that release of endogenous galanin during stress may have inhibited output of the BST, consistent with the suggestion that the BST may inhibit neuroendocrine and behavioral reactivity to stress.

However, these results may not be inconsistent with the studies discussed above that infer a facilitatory in- fluence of the BST on stress-reactivity. Glutamatergic afferents from BST have been demonstrated (Csaki et al. 2000). In addition, the BST and CeA are highly interconnected, and both contain a number of GABAergic neurons (Cullinan et al. 1993; Ju et al. 1989; Sun and Cassell 1993), as well as neurons expressing inhibitory neuropeptides, such as enkephalin (Day et al. 1999) and galanin (Gray and Magnuson 1987a,b). Subpopulations of GABAergic or peptidergic cells could function as local inhibitory interneurons within BST (Sun and Cassell 1993), or may form inhibitory interconnections with the CeA (Cullinan et al. 1993; Ju et al. 1989; Sun and Cassell 1993). Thus, it is possible that galanin could exert an inhibitory effect on a population of inhibitory interneurons, which themselves act upon a facilitatory glutamatergic output from the BSTL.

The facilitatory influence of galanin in the BSTL on behavioral and neuroendocrine stress reactivity is in distinct contrast to the attenuating influence demonstrated recently for galanin in the CeA (Khoshbouei et al. 2001). The BSTL and CeA are closely related components of the extended amygdala, and they share many functional and neuroanatomical characteristics. They have similar efferent targets in the brain stem and hypothalamus, and share a number of similar subpopulations of peptide- and GABA-expressing neurons. Nonetheless, several recent studies have suggested that these two limbic regions might have different functional roles in different contexts. It has been suggested that the BSTL plays a role in nonspecific anxiety, while CeA is involved in cue-conditioned fear (reviewed by Davis and Shi (1999)). Inhibition of the locus coeruleus blocked foot shock-induced c-fos expression in the CeA, but not in the BSTL, suggesting that the concurrent activation of these regions may occur by different afferent pathways (Passerin et al. 2000), consistent with the anatomical demonstration that noradrenergic innervation of the BST arises not from the LC, but from the medullary A1 and A2 cell groups (Delfs et al. 2000). Furthermore, systemic IL- $\beta$ administration activates distinct subsets of neurons in the BSTL and CeA, suggesting that there may be neurochemically distinct subpopulations of cells in the BSTL and CeA that are activated selectively by different stressful stimuli, and that may have different functional effects (Day et al. 1999). Thus, depending on the context and the specific nature of the initiating stimulus, a modulatory neurotransmitter such as galanin, acting in the CeA or BSTL, could have a variety of effects on behavioral and neuroendocrine reactivity.

These observations may be important in reconciling the seemingly inconsistent results generated in previous investigations of the effects of exogenous galanin on anxiety-like behaviors (Bing et al. 1993; Moller et al. 1999). One study showed that i.c.v. administration of galanin increased punished drinking, suggesting an anxiolytic effect (Bing et al. 1993). By contrast, in an- 
other experiment conducted by the same group, local administration of galanin into the amygdala produced a decrease in punished drinking, with no effect on the elevated-plus maze (Moller et al. 1999). Part of this discrepancy may arise from the fact that i.c.v. administration of drugs can affect multiple brain regions, which may elicit different or even opposing effects, as discussed above for the CeA and BSTL. Moreover, in the present study, we explicitly addressed a role for galanin in modulating stress-induced behavioral responsivity, measured as a reduction in social behavior and exploratory behavior following acute stress exposure. However, no stressor was applied in those previous studies, and it is possible that effects on baseline behavior and stressactivated behavior are different. The fact that M40 lacked effect on baseline behavior in the absence of stress in the present study, and the fact that high levels of neuronal activity are required for peptide release, both suggest that the modulatory influence of endogenous galanin in the BSTL may be exerted specifically in the context of stress-induced activation.

Whether galanin modulates behavioral and neuroendocrine stress reactivity by acting upon a common modulatory circuit in BSTL that projects to distinct behavioral and neuroendocrine regulatory pathways downstream, or by acting upon parallel circuits within BSTL that independently regulate behavioral and neuroendocrine response circuits, cannot be determined from the present results. It is clear, however, that the behavioral, affective and neuroendocrine components of the stress response are mediated and modulated in a variety of brain regions and by a variety of neurotransmitter systems. The data presented in this study, together with the results of our previous study, suggest a complex modulatory role for galanin in the CeA and BSTL, perhaps by interacting with norepinephrine or other monoaminergic, peptidergic or amino acid neurotransmitters. Such modulatory interactions are likely to play an important part in shaping the adaptive behavioral and physiologic responses to stress, in integrating the complex constellations of specific responses that are recruited by different stressors, or in regulating the nature and magnitude of the stress response in the face of repeated, extreme, or inappropriate activation. As such, galanin may be involved in the development or manifestation of stress-related illnesses such as depression, PTSD or other anxiety disorders, and could represent a novel target for therapeutic strategies aimed at the treatment of such disorders.

\section{ACKNOWLEDGMENTS}

Expert technical assistance was provided by Ms. Lauren Phillips and Ms. April Garcia. This work was supported by research grants from the National Institute of Mental Health (MH53851 and MH60118).

\section{REFERENCES}

Abercrombie ED, Jacobs BL (1987): Single-unit response of noradrenergic neurons in the locus coeruleus of freely moving cats. II. Adaptation to chronically presented stressful stimuli. J Neurosci 7:2844-2848

Aston-Jones G, Delfs J, Druhan J, Zhu Y (1999): The bed nucleus of the stria terminalis. A target site for noradrenergic actions in opiate withdrawal. Ann N Y Acad Sci 877:486-498

Bartfai T, Fisone G, Langel U (1992): Galanin and galanin antagonists: molecular and biochemical perspectives. Trends Pharmacol Sci 13:312-317

Bartfai T, Langel U, Bedecs K, Andell S, Land T, Gregersen S, Ahren B, Girotti P, Consolo S, Corwin R, Crawley J, Xu X, Wiesenfeld-Hallin Z, Hokfelt T (1993): Galaninreceptor ligand M40 peptide distinguishes between putative galanin-receptor subtypes. Proc Natl Acad Sci USA 90:11287-11291

Bing O, Moller C, Engel JA, Soderpalm B, Heilig M (1993): Anxiolytic-like actions of centrally administered galanin. Neurosci Lett 164:17-20

Branchek T, Smith KE, Walker MW (1998): Molecular biology and pharmacology of galanin receptors. Ann N Y Acad Sci 863:94-107

Branchek TA, Smith KE, Gerald C, Walker MW (2000): Galanin receptor subtypes. Trends Pharmacol Sci 21:109-117

Cecchi M, Khoshbouei H, Javors M, Morilak DA (2001): Modulatory effects of norepinephrine in the lateral bed nucleus of the stria terminalis on behavioral and neuroendocrine responses to acute stress. Neuroscience (In press)

Consolo S, Baldi G, Russi G, Civenni G, Bartfai T, Vezzani A (1994): Impulse flow dependency of galanin release in vivo in the rat ventral hippocampus. Proc Natl Acad Sci USA 91:8047-8051

Crawley J (1999): The role of galanin in feeding behavior. Neuropeptides 33:369-375

Crawley JN, Austin MC, Fiske SM, Martin B, Consolo S, Berthold M, Langel U, Fisone G, Bartfai T (1990): Activity of centrally administered galanin fragments on stimulation of feeding behavior and on galanin receptor binding in the rat hypothalamus. J Neurosci 10:3695-3700

Crawley JN, Robinson JK, Langel U, Bartfai T (1993): Galanin receptor antagonists M40 and C7 block galanininduced feeding. Brain Res 600:268-272

Csaki A, Kocsis K, Halasz B, Kiss J (2000): Localization of glutamatergic/aspartatergic neurons projecting to the hypothalamic paraventricular nucleus studied by retrograde transport of [3H]D-aspartate autoradiography. Neuroscience 101:637-655

Cullinan WE, Herman JP, Watson SJ (1993): Ventral subicular interaction with the hypothalamic paraventricular nucleus: evidence for a relay in the bed nucleus of the stria terminalis. J Comp Neurol 332:1-20

Davis M, Shi C (1999): The extended amygdala: are the central nucleus of amygdala and the bed nucleous of the stria terminails differentially involved in fear versus anxiety? Ann N Y Acad Sci 877:281-291

Davis M, Walker D, Lee Y (1997a): Roles of the amygdala and bed nucleus of the stria terminalis in fear and anxi- 
ety measured with the acoustic startle reflex. Possible relevance to PTSD. Ann N Y Acad Sci 821:305-331

Davis M, Walker DL, Lee Y (1997b): Amygdala and bed nucleus of the stria terminalis: Differential roles in fear and anxiety measured with the acoustic startle reflex. Phil Trans R Soc Lond B 352:1675-1687

Day HE, Curran EJ, Watson SJ, Akil H (1999): Distinct neurochemical populations in the rat central nucleus of the amygdala and bed nucleus of the stria terminalis: evidence for their selective activation by interleukin-1beta. J Comp Neurol 413:113-128

Delfs J, Zhu Y, Druhan J, Aston-Jones G (2000): Noradrenaline in the ventral forebrain is critical for opiate withdrawal-induced aversion. Nature 403:430-434

Diaz-Cabiale Z, Narvaez JA, Finnman UB, Bellido I, Ogren SO, Fuxe K (2000a): Galanin-(1-16) modulates 5-HT1A receptors in the ventral limbic cortex of the rat. Neuroreport 11:515-519

Diaz-Cabiale Z, Narvaez JA, Yanaihara N, Gonzalez-Baron $S$, Fuxe K (2000b): Galanin/alpha2-receptor interactions in central cardiovascular control. Neuropharmacology 39:1377-1385

Dunn JD (1987): Plasma corticosterone responses to electrical stimulation of the bed nucleus of the stria terminalis. Brain Res 407:327-331

Fernandes C, File SE (1996): The influence of open arm ledges and maze experience in the elevated plus-maze. Pharmacol Biochem Behav 54:31-40

Fernandes C, McKittrick CR, File SE, McEwen BS (1997): Decreased 5-HT1A and increased 5-HT2A receptor binding after chronic corticosterone associated with a behavioural indication of depression but not anxiety. Psychoneuroendocrinology 22:477-491

File S (1980): The use of social interaction as a method for detecting anxiolytic activity of chlordiazepoxide-like drugs. J Neurosci Methods 2:219-238

File S (1995): Animal models of different anxiety states. Adv Biochem Psychopharmacol 48:93-113

File S, Fluck E (1994): Handling alters habituation and response to stimulus change in the holeboard. Pharmacol Biochem Behav 49:449-453

File S, Hyde J (1978): Can social interaction be used to measure anxiety? Br J Pharmacol 62:19-24

File S, Hyde J (1979): A test of anxiety that distinguishes between the actions of benzodiazepines and those of other minor tranquilisers and of stimulants. Pharmacol Biochem Behav 11:65-69

File SE (1984): The validation of animal tests of anxietypharmacological implications. Pol J Pharmacol Pharm 36:505-512

File SE, Gonzalez LE, Gallant R (1999): Role of the dorsomedial hypothalamus in mediating the response to benzodiazepines on trial 2 in the elevated plus-maze test of anxiety. Neuropsychopharmacology 21:312-320

Forray MI, Bustos G, Gysling K (1999): Noradrenaline inhibits glutamate release in the rat bed nucleus of the stria terminalis: in vivo microdialysis studies. J Neurosci Res 55:311-320

Gray TS, Magnuson DJ (1987a): Galanin-like immunoreactivity within amygdaloid and hypothalamic neurons that project to the midbrain central grey in rat. Neurosci Lett 83:264-268

Gray TS, Magnuson DJ (1987b): Neuropeptide neuronal efferents from the bed nucleus of the stria terminalis and central amygdaloid nucleus to the dorsal vagal complex in the rat. J Comp Neurol 262:365-374

Gray TS, Piechowski RA, Yracheta JM, Rittenhouse PA, Bethea CL, Van de Kar LD (1993): Ibotenic acid lesions in the bed nucleus of the stria terminalis attenuate conditioned stress-induced increases in prolactin, ACTH and corticosterone. Neuroendocrinology 57:517-524

Gustafson EL, Smith KE, Durkin MM, Gerald C, Branchek TA (1996): Distribution of a rat galanin receptor mRNA in rat brain. Neuroreport 7:953-957

Herman JP, Cullinan WE (1997): Neurocircuitry of stress: central control of the hypothalamo-pituitary-adrenocortical axis. Trends Neurosci 20:78-84

Herman JP, Cullinan WE, Watson SJ (1994): Involvement of the bed nucleus of the stria terminalis in tonic regulation of paraventricular hypothalamic CRH and AVP mRNA expression. J Neuroendocrinol 6:433-442

Herman JP, Prewitt CM, Cullinan WE (1996): Neuronal circuit regulation of the hypothalamo-pituitary-adrenocortical stress axis. Crit Rev Neurobiol 10:371-394

Holets VR, Hokfelt T, Rokaeus A, Terenius L, Goldstein M (1988): Locus coeruleus neurons in the rat containing neuropeptide $\mathrm{Y}$, tyrosine hydroxylase or galanin and their efferent projections to the spinal cord, cerebral cortex and hypothalamus. Neuroscience 24:893-906

Holmes PV, Blanchard DC, Blanchard RJ, Brady LS, Crawley JN (1995): Chronic social stress increases levels of preprogalanin mRNA in the rat locus coeruleus. Pharmacol Biochem Behav 50:655-660

Hooi SC, Maiter DM, Martin JB, Koenig JI (1990): Galaninergic mechanisms are involved in the regulation of corticotropin and thyrotropin secretion in the rat. Endocrinol 127:2281-2289

Ju G, Swanson L, Simerly R (1989): Studies on the cellular architecture of the bed nuclei of the stria terminalis in the rat II. Chemoarchitecture. J Comp Neurol 280:603-621

Khoshbouei H, Cecchi M, Morilak DA (2000): Amplification of the noradrenergic response to stress elicits galaninmediated anxiolytic effects in central amygdala that counteract the anxiogenic influence of norepinephrine. Soc Neurosci Abstr 26:1154

Khoshbouei H, Cecchi M, Morilak DA (2001): Amplification of the noradrenergic response to stress elicits galaninmediated anxiolytic effects in central amygdala. Pharmacol Biochem Behav (in press)

Kozicz T (1999): Synaptic interactions between galanin and axon terminals immunopositive for tyrosine hydroxylase and dopamine B-hydroxylase in the bed nucleus of the stria terminalis in the rat. Soc Neurosci Abstr 25:2220

Lee Y, Davis M (1997): Role of the hippocampus, the bed nucleus of the stria terminalis, and the amygdala in the excitatory effect of corticotropin-releasing hormone on the acoustic startle reflex. J Neurosci 17:6434-6446

McDonald M, Crawley J (1996): Galanin receptor antagonist M40 blocks galanin-induced choice accuracy deficits on adelayed-nonmatching-to-position task. Behav Neurosci 110:1025-1032 
McDonald MP, Willard LB, Wenk GL, Crawley JN (1998): Coadministration of galanin antagonist M40 with a muscarinic $\mathrm{M}_{1}$ agonist improves delayed nonmatching to position choice accuracy in rats with cholinergic lesions. J Neurosci 18:5078-5085

Melander T, Hokfelt T, Nilsson S, Brodin E (1986a): Visualization of galanin binding sites in the rat central nervous system. Eur J Pharmacol 124:381-382

Melander T, Hokfelt T, Rokaeus A (1986b): Distribution of galaninlike immunoreactivity in the rat central nervous system. J Comp Neurol 248:475-517

Melander T, Hokfelt T, Rokaeus A (1986c): Distribution of galaninlike immunoreactivity in the rat central nervous system. J Comp Neurol 248:475-517

Melander T, Hokfelt T, Rokaeus A, Cuello AC, Oertel WH, Verhofstad A, Goldstein M (1986d): Coexistence of galanin-like immunoreactivity with catecholamines, 5-hydroxytryptamine, GABA and neuropeptides in the rat CNS. J Neurosci 6:3640-3654

Miller MA, Kolb PE, Raskind MA (1993a): Extra-hypothalamic vasopressin neurons coexpress galanin messenger RNA as shown by double in situ hybridization histochemistry. J Comp Neurol 329:378-384

Miller MA, Kolb PE, Raskind MA (1993b): Testosterone regulates galanin gene expression in the bed nucleus of the stria terminalis. Brain Res 611:338-341

Miller MA, Kolb PE, Raskind MA (1997): GALR1 galanin receptor mRNA is co-expressed by galanin neurons but not cholinergic neurons in the rat basal forebrain. Brain Res Mol Brain Res 52:121-129

Moga MM, Saper CB (1994): Neuropeptide-immunoreactive neurons projecting to the paraventricular hypothalamic nucleus in the rat. J Comp Neurol 346:137-150

Moller C, Sommer W, Thorsell A, Heilig M (1999): Anxiogenic-like action of galanin after intra-amygdala administration in the rat. Neuropsychopharmacology 21:507-512

Morilak DA, Fornal CA, Jacobs BL (1987): Effects of physiological manipulations on locus coeruleus neuronal activity in freely moving cats. I. Thermoregulatory challenge. Brain Res 422:17-23

Mufson EJ, Cochran E, Benzing W, Kordower JH (1993): Galaninergic innervation of the cholinergic vertical limb of the diagonal band (Ch2) and bed nucleus of the stria terminalis in aging, Alzheimer's disease and Down's syndrome. Dementia 4:237-250

Mufson EJ, Deecher DC, Basile M, Izenwasse S, Mash DC (2000): Galanin receptor plasticity within the nucleus basalis in early and late Alzheimer's disease: an in vitro autoradiographic analysis. Neuropharmacology 39:1404-1412

Mufson EJ, Kahl U, Bowser R, Mash DC, Kordower JH, Deecher DC (1998): Galanin expression within the basal forebrain in Alzheimer's disease. Comments on therapeutic potential. Ann N Y Acad Sci 863:291-304

Pacak K, Palkovits M, Kvetnansky R, Fukuhara K, Kopin IJ, Goldstein DS (1993): Effects of single or repeated immobilization on release of norepinephrine and its metabolites in the central nucleus of the amygdala in conscious rats. Neuroendocrinol 57:623-633
Passerin AM, Cano G, Rabin BS, Delano BA, Napier JL, Sved AF (2000): Role of locus coeruleus in foot shock-evoked Fos expression in rat brain. Neuroscience 101:1071-1082

Pieribone V, Xu Z, Zhang X, Hokfelt T (1998): Electrophysiologic effects of galanin on neurons of the central nervous system. Ann N Y Acad Sci 863:264-273

Pieribone VA, Xu ZQ, Zhang X, Grillner S, Bartfai T, Hokfelt $\mathrm{T}$ (1995): Galanin induces a hyperpolarization of norepinephrine-containing locus coeruleus neurons in the brainstem slice. Neurosci 64:861-874

Sawada S, Yamamoto C (1981): Postsynaptic inhibitory actions of catecholamines and opioid peptides in the bed nucleus of the stria terminalis. Exp Brain Res 41:264-270

Sawchenko PE, Pfeiffer SW (1988): Ultrastructural localization of neuropeptide $\mathrm{Y}$ and galanin immunoreactivity in the paraventricular nucleus of the hypothalamus in the rat. Brain Res 474:231-245

Seutin V, Verbanck P, Massotte L, Dresse A (1989): Galanin decreases the activity of locus coeruleus neurons in vitro. Eur J Pharmacol 164:373-376

Shaham Y, Erb S, Stewart J (2000): Stress-induced relapse to heroin and cocaine seeking in rats: a review. Brain Res Rev 33:13-33

Shekhar A, Keim SR (2000): The bed nucleus of the stria terminalis: putative site for anxiety in lactate-induced panic responses in panic-prone rats. Soc Neurosci Abstr 26:2042

Shih CD, Chan SH, Chan JY (1996): Participation of endogenous galanin in the suppression of baroreceptor reflex response by locus coeruleus in the rat. Brain Res 721:76-82

Sun N, Cassell MD (1993): Intrinsic GABAergic neurons in the rat central extended amygdala. J Comp Neurol 330:381-404

Sweerts B, Jarrott B, Lawrence A (1999): Expression of preprogalanin mRNA following acute and chronic restraint stress in brains of normotensive and hypertensive rats. Brain Res Mol Brain Res 69:113-123

Sweerts BW, Jarrott B, Lawrence AJ (2000): Acute and chronic restraint stress: effects on $\left[{ }^{125} \mathrm{I}\right]$-galanin binding in normotensive and hypertensive rat brain. Brain Res 873:318-329

Tatemoto K, Rokaeus A, Jornvall H, McDonald TJ, Mutt V (1983): Galanin - a novel biologically active peptide from porcine intestine. FEBS Lett 164:124-128

Waters SM, Krause JE (2000): Distribution of galanin-1, -2 and -3 receptor messenger RNAs in central and peripheral rat tissues. Neuroscience 95:265-271

Xu Z-QD, Shi T-JS, Hokfelt T (1998): Galanin/GMAP- and NPY-like immunoreactivities in locus coeruleus and noradrenergic nerve terminals in the hippocampal formation and cortex with notes on the galanin-R1 and -R2 receptors. J Comp Neurol 392:227-251

Xu ZQ, Ma X, Soomets U, Langel U, Hokfelt T (1999): Electrophysiological evidence for a hyperpolarizing, galanin (1-15)-selective receptor on hippocampal CA3 pyramidal neurons. Proc Natl Acad Sci USA 96:14583-14587 